\title{
A logic framework for evaluating social determinants of health interventions in primary care
}

\author{
Steven S. Coughlin ${ }^{1,2}$, Paul Mann ${ }^{2,3}$, Marlo Vernon ${ }^{4}$, Lufei Young ${ }^{5}$, Deepak Ayyala ${ }^{1}$, Richard Sams ${ }^{6}$, \\ Christos Hatzigeorgiou ${ }^{7}$
}

${ }^{1}$ Department of Population Health Sciences, Medical College of Georgia, ${ }^{2}$ Institute of Public and Preventive Health, Augusta University, Augusta, GA, USA; ${ }^{3}$ Department of Pediatrics, Medical College of Georgia, Augusta University, Augusta, GA, USA; ${ }^{4}$ Department of Undergraduate Health Professions, College of Allied Health Sciences, ${ }^{5}$ College of Nursing, Augusta University, Augusta, GA, USA; ${ }^{6}$ Department of Family Medicine, Medical College of Georgia, Augusta University, Augusta, GA, USA; ${ }^{7}$ Division of General Internal Medicine, Medical College of Georgia, Augusta University, Augusta, GA, USA

Contributions: (I) Conception and design: SS Coughlin; (II) Administrative support: None; (III) Provision of study materials or patients: SS Coughlin; (IV) Collection and assembly of data: SS Coughlin; (V) Data analysis and interpretation: D Ayyala, SS Coughlin; (VI) Manuscript writing: All authors; (VII) Final approval of manuscript: All authors.

Correspondence to: Steven S. Coughlin, PhD, MPH. Professor, Department of Population Health Sciences, Medical College of Georgia, Augusta University, 1120 15th Street, Augusta, GA 30912, USA. Email: scoughlin@augusta.edu.

Background: Increasing efforts have been made in primary care settings to screen for a broad array of social determinants of health including inadequate food and nutrition, lack of education, unemployment, and inadequate housing, and to refer patients to community resources. Core tenets of primary care include integration with community resources.

Methods: In the course of designing a randomized controlled trial of the effectiveness of a social determinants of health intervention aimed at adult, at-risk, African American primary care clinic patients, our research team developed a logic model to assist with the evaluation of the intervention.

Results: In this article, we describe the logic model including elements of the intervention, mediator variables, and outcome variables.

Conclusions: The proposed logic framework is likely to be helpful for planning, conducting, and evaluating social determinants of health interventions in primary care settings.

Keywords: African Americans; chronic disease; education; food insecurity; poverty; patient-centered medical home; primary care; unemployment

Received: 06 May 2019; Accepted: 06 September 2019; Published: 18 September 2019.

doi: 10.21037/jhmhp.2019.09.03

View this article at: http://dx.doi.org/10.21037/jhmhp.2019.09.03

\section{Introduction}

Increasing efforts have been made in primary care settings to screen for a broad array of social determinants of health including inadequate food and nutrition, lack of education, unemployment, and inadequate housing, and to refer patients to community resources [e.g., food pantries, job training centers, housing programs, and general educational development (GED) programs] (1-5). Seen from this perspective, quality primary care includes the amelioration of the harmful health effects of income inequalities and lack of basic needs, and primary care settings are an appropriate environment for assessing and intervening on social determinants of health (1-5). In the course of designing a randomized controlled trial of the effectiveness of a social determinants of health intervention aimed at adult, at-risk, African American primary care clinic patients, our research team developed a logic model to assist with the evaluation of the intervention. In this article, we describe the logic model including elements of the intervention, mediator variables, 
and outcome variables. We begin with an overview of the rationale for the intervention trial.

\section{The rationale for addressing social determinants of illness in primary care}

It is widely appreciated that the social context in which people live and work influences their health (1). The World Health Organization defined the social determinants of health as the "conditions in which people are born, grow, work, live and age, and the wider set of forces and systems shaping the conditions of daily life" (2). Adverse childhood experiences (ACEs), including exposure to domestic violence, parental incarceration and mental health, are strongly associated with adverse health consequences later in life (6). Addressing social determinants of health has largely been left up to disciplines such as health policy, social services, and public health. However, in primary care, screening strategies have been developed for specific psychosocial issues such as substance abuse and intimate partner violence (1).

Page-Reeves et al. (5) developed an 11-item survey to screen patients for social determinants of health in 3 family medicine clinics in Albuquerque, New Mexico. The questions included: (I) in the past 2 months, did you or others you live with eat smaller meals or skip meals because you didn't have money for food? (II) Are you homeless or worried that you might be in the future? (III) Do you have trouble paying for your utilities (gas, electricity, phone)? (IV) Do you have trouble finding or paying for a ride? (V) Do you need daycare, or better daycare, for your kids? (VI) Are you unemployed or without regular income? (VII) Do you need help finding a better job? (VIII) Do you need help getting more education? (IX) Are you concerned about someone in your home using drugs or alcohol? $(\mathrm{X})$ Do you feel unsafe in your daily life? (XI) Is anyone in your home threatening or abusing you? A total of 3,048 patients were screened over a 90 day period. Forty-six percent of patients screened positive for a least 1 area of social need, and $63 \%$ of those had multiple needs. Medical assistants and community health workers then offered to connect patients with appropriate services and resources to address the identified needs. The pilot demonstrated that it is feasible for a clinic to assess primary care patients for social needs and to refer patients for assistance. Roberts et al. (7) described a paradigm to identify childhood trauma that emphasizes awareness of the effects of ACEs on later health and an emphasis on screening.

Pinto et al. (8) developed a set of 14 questions that covered a range of social determinants of health. These were translated into 13 languages. The survey was selfadministered to a convenience sample of 407 primary care clinic patients in Toronto. In a subsequent implementation across 5 clinics, 10,536 patients were surveyed. Only 724 (6.9\%) declined to participate. The authors concluded that it is feasible and acceptable to collect data on social determinants of health through a self-administered survey, and to link them to a patient's chart (8).

Other studies have utilized electronic medical records to address social determinants of health in clinical settings $(3,4)$. For example, Bazemore et al. (4) incorporated geocoded social determinants into electronic medical records to promote patient health. Neighborhood characteristics contribute to the social environment experienced by individual patients. Living in a disadvantaged social environment may have an independent negative influence on health and health behaviors. Inclusion of place based social determinants provides care providers with an environmental analysis of health risk.

As defined by the Institute of Medicine (IOM) (9) the social environment may influence health behavior by, "shaping norms, enforcing patterns of social control, providing or not providing environmental opportunities to engage in particular behaviors, reducing or producing stress, and placing constraints on individual choice". The environmental context of living in an area of low or under-employment, high crime, residential crowding, and poorer living conditions contributes to a state of chronic psychosocial stress (10-13). Accordingly, behavioral and metabolic risk factors are increased disproportionately among those with high psychosocial chronic stress leading to a strain on the coping abilities of individuals (14-16). The inadequate structural and functional support associated with disadvantaged neighborhoods has also been linked to cardiac death and all-cause mortality (17). One hypothesized mechanism for the relationship between chronic stress and poor health outcomes lies within the hypothalamus-pituitary-adrenal (HPA) pathway. Increased HPA dysfunction has been identified with lower socioeconomic status, higher cortisol variability, and increased measurements of central adiposity $(15,18)$. Chronic stress due to a disadvantaged social environment may independently negatively impact health outcomes.

\section{The rationale for selecting African Americans as the target population}

The rationale for targeting at-risk African Americans in 
the trial is based upon their higher risk of adverse health outcomes and premature mortality. Life expectancy in the U.S. in 2015 was 75.7 years for African Americans compared to 87.7 years for Asian/Pacific Islanders and 79.2 years for whites (19). The disparity in life expectancy, which is particularly pronounced for African American men, is driven by marked racial disparities in leading causes of death such as heart disease, diabetes, and homicide (19). African Americans also experience pronounced disparities in cancer mortality (20-24).

African Americans have poorer cardiovascular health and higher cardiovascular disease (CVD) mortality than nonHispanic whites. The high burden of CVD among African Americans is a primary cause of disparities in life expectancy between African Americans and whites (25). The higher prevalence of CVD risk factors (e.g., hypertension, diabetes mellitus, and obesity) underlies the relatively earlier age of onset of CVDs among African Americans. Hypertension is highly prevalent among African Americans and contributes to disparities in stroke, heart failure, and peripheral artery disease (25). The prevalence of diagnosed and undiagnosed hypertension among African American men (42.4\%) and women $(44 \%) \geq 20$ years of age is among the highest in the world (25).

African American men develop diabetes mellitus 1.52 times more often than white men, and African American women are 2.14 times more likely to develop diabetes than white women (25). The combined prevalence of diagnosed and undiagnosed type 2 diabetes mellitus is $21.8 \%$ in African Americans and 11.3\% in non-Hispanic whites (26). Blacks are twice as likely to die from diabetes than nonHispanic whites (27). In a study of racial disparities in diabetes mortality in the 50 most populous U.S. cities, blacks had statistically significantly higher mortality rates compared to whites in 39 of the 41 cities included in analyses (27).

Obesity rates are higher among African Americans than whites. Among adults $\geq 20$ years of age, African American women had the highest rates of obesity at $58 \%$, followed by African American men (38\%), white men (34\%), and white women $(33 \%)(28)$.

Although reduced obesity, healthy diet, increased physical activity, and use of health care services can improve population health and health equity, such factors are influenced by social determinants such as income, employment, and education $(19,20)$. Neighborhood socioeconomic status (SES) is inversely related to diabetes and hypertension. African Americans are four times more likely than whites to live in lowest SES neighborhoods (20).
Poverty rates are two times higher among African Americans (25.4\%) compared to non-Hispanic whites (10.4\%) (19). Unemployment rates are more than two times higher among African Americans compared to nonHispanic whites (19). There are also substantial disparities in educational attainment. Fewer African Americans graduate from high school $(72.5 \%)$ than non-Hispanic whites $(87.2 \%)(20)$.

\section{Methods}

\section{Description of the logic framework}

In developing the logic framework for evaluating the effectiveness of the social determinants of health intervention, we began by enumerating key elements of the intervention (Table 1). These include screening and referral for food insecurity, unemployment, lack of education, inadequate housing, social support and social network.

\section{Result}

\section{Food insecurity}

Food insecurity is an important social determinant of health (29). The U.S. Department of Agriculture defines food insecurity as "a household-level economic and social condition of limited or uncertain access to adequate food" (30). In 2016, 12.3\% of US households reported being food insecure at some point in the year (31). The prevalence of food insecurity was $22.6 \%$ among non-Hispanic blacks and $31.6 \%$ in households headed by single women (31). There are different stages of the severity of food insecurity starting with not being able to buy and eat what one would like due to income-related constraints. The next stage involves a decrease in food quantity, attempts to make food last until there is money to buy more, and hunger (32). Low-income, ethnic minority and female-headed households are at greatest risk for food insecurity $(31,33)$.

People who experience food insecurity often consume a nutrient-poor diet, which may contribute to obesity, diabetes, heart disease, and hypertension $(29,33,34)$. In order to buy food or because of budget constraints, lowincome families may postpone medical care and underuse medicine (29). Food insecurity is associated with stress, anxiety, depression and psychological distress $(32,35)$.

Federal programs to address food insecurity include the Supplemental Nutrition Assistance Program (SNAP), the Special Supplemental Nutrition Program for Women, 
Table 1 Logic framework for social determinants of health intervention

Intervention
Screening and referral for food insecurity, unemployment, lack
of education, and inadequate housing
Potential mediators
Decreased food insecurity
Increased employment
Increased education opportunities
Decreased substandard housing
Reduced stressors in the areas of housing, education,
unemployment, and food insecurity*
Social support, social network
Primary and secondary outcomes
Reduced emergency department visits
Reduced hospitalizations
Improved patient satisfaction with primary care
Chronic disease indicators (e.g., HbA1c)
Receipt of preventive services*
Improved self-reported overall health
mental health)
Lower healthcare costs

*, opportunities for learning, improved standard of living, improved living conditions, improved nutrition; **, e.g., mammogram, colorectal cancer screening, immunizations.

Infants, and Children, the National School Lunch Program, the Child and Adult Care Food Program, and Meals on Wheels (29,36).

\section{Unemployment, lack of education, and low-income}

Socioeconomic factors such as unemployment, lack of education, poverty, and income inequality are among the most important social determinants of health. It has been known for over two hundred years that low-income people are at increased risk of an array of adverse health outcomes and more likely to die prematurely. Numerous studies have documented a socioeconomic gradient: at each step along the socioeconomic ladder, there are improved health outcomes over the rung below $(37,38)$. In addition, the SES gradient does not appear to be explained by differences in access to health care. Steep gradients have been observed even among groups of people who have adequate access to health care, housing, and transportation (38). There are identifiable pathways through which social inequalities appear to lead to health inequalities. In the United States, for example, states with the most unequal income distributions invest less in public education and spend less on social safety nets (38). Policies that improve individual life opportunities such as investment in basic education, affordable housing, and income security are likely to reduce health inequalities (39).

\section{Inadequate bousing}

In January 2017, there were an estimated 553,742 homeless people in the United States (40). The rate of people experiencing homelessness on a given night is about 17 per 10,000 people. Most homeless people lived in some form of shelter or in transitional housing. However, about 34 percent $(192,875$ people) lived in a place not meant for human habitation such as the street or an abandoned building.

Many homeless people suffer from comorbid substance abuse and other medical and psychiatric (1). However, homeless populations are very heterogeneous, and many people who transition in and out of homelessness do not suffer from substance abuse or dependence or other serious mental illness (41). They may face other profound life challenges, however. People challenged by homelessness are living with several losses including the loss of a home, employment, economic security, health or well-being and personal security. For people who are homeless, assistance programs consist of housing, emergency shelter, food services, employment assistance, peer support, medical care, and mental health services including those aimed at recovery from substance-related disorders $(1,2)$. Such programs are administered by a variety of federal and state agencies, nongovernmental organizations, faith-based organizations, and veteran service organizations $(2,3)$.

\section{Social support and social network}

Social support and social network are another key element of the social determinants of health. Presence of social network and high levels of social support have been shown to be a protective factor for maintaining good health and quality of life $(42,43)$. Evidence showed social support was positively associated with physical and mental health, good 
self-rated health, reduced depression, and good quality of life, which are important indicators of overall wellbeing $(42,43)$. In addition, social support and network play vital roles in patients' navigating healthcare system and healthcare experiences (44). Findings show that patients who had adequate social support from their networks had more healthcare access, treatment options, more engaged to their care, more adhered to treatment regimens, fostered more productive relationships with their healthcare providers (44). Effective primary care demands patient/ family's time and attention to improve medical knowledge, communication skills, a proactive attitude to engage their self-care. Without adequate social support through their networks, it is impossible for patients having time and attention to build, refine, and leverage their ability navigating the health care system.

\section{Potential mediators}

The logic framework for the social determinants of health intervention enumerates several potential mediators including decreased food insecurity, increased employment, increased opportunities for education (e.g., GED or continuing education), decreased substandard housing, social support and social network (Table 1). Opportunities for learning and improved standard of living, living conditions, and nutrition may all help to reduce risk of illness and improve patient self-management of chronic conditions. In addition, such mediators may reduce stressors in the areas of housing, education, unemployment, and food insecurity that contribute to psychological distress.

Primary and secondary outcomes. Based upon this literature review, our research team identified several primary and secondary outcomes that may be positively impacted by the social determinants of health intervention. These include reduced emergency department (ED) visits, reduced hospitalizations, and improved patient satisfaction with primary care (Table 1). Other potential outcomes include improved chronic disease indicators (e.g., HbA1c); receipt of preventive services such as mammograms, colorectal cancer screening, and immunizations; improved self-reported overall health; improved physical and mental health; reduced "no show" rates in primary care clinics; and lower health care costs.

\section{Discussion}

Core tenants of primary care included integration with community resources $(45,46)$. This has been interpreted to mean "other healthcare entities such as hospitals, specialists, other service providers, urgent care" (45). However, in order to address social determinants of health, our logic framework extends this to other community resources such as food banks and resources for housing assistance.

The logic framework did not consider all possible outcomes and mediators. For example, mistrust of healthcare providers is one potential mediating variable. It is possible that interventions which address social determinants of health may improve health outcomes such as patient satisfaction with care and chronic disease indicators in part by ameliorating medical mistrust. African Americans have been found to have higher levels of medical mistrust, conceptualized as an individual's lack of trust in the health care system, including providers and facilities $(47,48)$. Medical mistrust is a barrier to appropriate health care utilization and may play an important role in how individuals assess health care experiences and access preventive health services $(47,49)$.

Additionally, improving life-expectancy and reducing health outcome disparities for African Americans will require addressing a substantial number of medical treatment discrepancies seen between African Americans and other racial groups $(50,51)$. For a wide range of medical diagnoses ranging from mental health issues to cancer and CVD, African Americans have health outcomes worse than their non-Black peers and may receive inferior medical treatment $(50,52)$. Understanding how and why medical providers provide different medical care for their African American patients is essential to optimizing their health and quality of life.

Primary care enhances equity in health because its functions (first contact access, patient-focused care over time, comprehensiveness, and coordination of care) are especially beneficial to disadvantaged populations (53). In the United States, primary care figures prominently in the patient-centered medical home, which has emerged as an important part of health care reform. The patientcentered medical home "aims to personalize, prioritize and integrate care to improve the health of whole people, families, communities and populations" (45). The National Committee for Quality Assurance (NCQA) has developed standards and guidelines for patient-centered medical homes. This includes competency in understanding population needs and community resources as well as community resource lists and assessments (NCQA). Similarly, the Joint Commission's Primary Medical 
Home Certification highlights several core functions and attributes including patient-centered care (relationshipbased care focused on the whole person and understanding and respecting each patient's needs, culture, values and preferences), comprehensive care (a team of providers (may include physicians, advanced practice nurses, physician assistants, nurses, pharmacists, nutritionists, mental health workers, social workers and others) who work to meet each patient's physical and mental health care needs, and coordinated care (care that is coordinated across the broader health care system, including specialty care, hospitals, home care and the provision of community and support services).

Caution should be exercised when designing an intervention study to evaluate the effect of social determinants. Observational studies conducted previously in the primary care center can be used as the control arm, circumventing the ethical issues of non-intervention. Using the observational studies as prior information, effectiveness of the interventions can be statistically validated. As the mediators in the logic framework can be affected by more than one intervention, interaction effects can be reduced through proper design. Identifying sub-populations matching the demographics of the patients in the observational study can help mitigate some of the confounding effects.

\section{Conclusions}

The proposed logic framework is likely to be helpful for planning, conducting, and evaluating social determinants of health interventions in primary care settings.

\section{Acknowledgments}

Funding: None.

\section{Footnote}

Conflicts of Interest: All authors have completed the ICMJE uniform disclosure form (available at http://dx.doi. org/10.21037/jhmhp.2019.09.03). SSC serve as an unpaid Associate Editor of fournal of Hospital Management and Health Policy. The other authors have no conflicts of interest to declare.

Ethical Statement: The authors are accountable for all aspects of the work in ensuring that questions related to the accuracy or integrity of any part of the work are appropriately investigated and resolved.
Open Access Statement: This is an Open Access article distributed in accordance with the Creative Commons Attribution-NonCommercial-NoDerivs 4.0 International License (CC BY-NC-ND 4.0), which permits the noncommercial replication and distribution of the article with the strict proviso that no changes or edits are made and the original work is properly cited (including links to both the formal publication through the relevant DOI and the license). See: https://creativecommons.org/licenses/by-nc-nd/4.0/.

\section{References}

1. Garg A, Jack B, Zuckerman B. Addressing the social determinants of health within the patient-centered medical home: lessons from pediatrics. JAMA 2013;309:2001-2.

2. World Health Organization. World conference on social determinants of health: case studies on social determinants. Available online: http://www.who.int/sdhconference/ resources/case_studies/en/

3. Gottlieb LM, Tirozzi KJ, Manchanda R, et al. Moving electronic medical records upstream: incorporating social determinants of health. Am J Prev Med 2015;48:215-8.

4. Bazemore AW, Cottrell EK, Gold R, et al. "Community vital signs": incorporating geocoded social determinants into electronic records to promote patient and population health. J Am Med Inform Assoc 2016;23:407-12.

5. Page-Reeves J, Kaufman W, Bleecker M, et al. Addressing social determinants of health in a clinic setting: the WellRx pilot in Albuquerque, New Mexico. J Am Board Fam Med 2016;29:414-8.

6. Hughes K, Bellis MA, Hardcastle KA, et al. The effect of multiple adverse childhood experiences on health: a systematic review and meta-analysis. Lancet Public Health 2017;2:e356-66.

7. Roberts SJ, Chandler GE, Kalmakis K. A model for trauma-informed primary care. J Am Assoc Nurse Pract 2019;31:139-44.

8. Pinto AD, Glattstein-Young G, Mohamed A, et al. Building a foundation to reduce health inequities: routine collection of sociodemographic data in primary care. J Am Board Fam Med 2016;29:348-55.

9. Institute of Medicine (US) Committee on Assuring the Health of the Public in the 21st Century. The future of the public's health in the 21st century. Washington: National Academies Press, 2002.

10. Rogers RG, Hummer RA, Nam CB, et al. Demographic, socioeconomic, and behavioral factors affecting ethnic mortality by cause. Social Forces 1996,74:1419-38. 
11. Dana RH. Multicultural assessment perspectives for professional psychology. Boston: Simon \& Schuster, 1993.

12. Baum A, Garofalo JP, Yali AM. Socioeconomic status and chronic stress. Does stress account for SES effects on health? Ann N Y Acad Sci 1999;896:131-44.

13. Anderson NB, Armstead CA. Toward understanding the association of socioeconomic status and health: a new challenge for the biopsychosocial approach. Psychosom Med 1995;57:213-25.

14. Lantz PM, House JS, Lepkowski JM, et al. Socioeconomic factors, health behaviors, and mortality: results from a nationally representative prospective study of US adults. JAMA 1998;279:1703-8.

15. Rozanski A, Blumenthal JA, Davidson KW, et al. The epidemiology, pathophysiology, and management of psychosocial risk factors in cardiac practice: the emerging field of behavioral cardiology. J Am Coll Cardiol 2005;45:637-51.

16. Pampel FC, Krueger PM, Denney JT. Socioeconomic disparities in health behaviors. Annu Rev Sociol 2010;36:349-70.

17. Rozanski A, Blumenthal JA, Kaplan J. Impact of psychological factors on the pathogenesis of cardiovascular disease and implications for therapy. Circulation 1999;99:2192-217.

18. García-León MÁ, Pérez-Mármol JM, Gonzalez-Pérez $\mathrm{R}$, et al. Relationship between resilience and stress: Perceived stress, stressful life events, HPA axis response during a stressful task and hair cortisol. Physiol Behav 2019;202:87-93.

19. Singh GK, Daus GP, Allender M, et al. Social determinants of health in the United States: addressing major health inequality trends for the nation, 1935-2016. Int J MCH AIDS 2017;6:139-64.

20. Noonan AS, Velasco-Mondragon HE, Wagner FA. Improving the health of African Americans in the USA: an overdue opportunity for social justice. Public Health Rev 2016;37:12.

21. Coughlin SS, Blumenthal DS, Seay SJ, et al. Toward the elimination of colorectal cancer disparities among African Americans. J Racial Ethn Health Disparities 2016;3:555-64.

22. Coughlin SS, Yoo W, Whitehead MS, et al. Advancing breast cancer survivorship among African-American women. Breast Cancer Res Treat 2015;153:253-61.

23. Coughlin SS, Matthews-Juarez P, Juarez PD, et al. Opportunities to address lung cancer disparities among African Americans. Cancer Med 2014;3:1467-76.
24. Smith ZL, Eggener SE, Murphy AB. African-American prostate cancer disparities. Curr Urol Rep 2017;18:81.

25. Carnethon MR, Pu J, Howard G, et al. Cardiovascular health in African Americans: a scientific statement from the American Heart Association. Circulation 2017;136:e393-423.

26. Menke A, Casagrande S, Geiss L, et al. Prevalence of and trends in diabetes among adults in the United States, 1988-2012. JAMA 2015;314:1021-9.

27. Rosenstock S, Whitman S, West JF, et al. Racial disparities in diabetes mortality in the 50 most populous US cities. J Urban Health 2014;91:873-85.

28. Benjamin EJ, Blaha MJ, Chiuve SE, et al. Heart disease and stroke statistics-2017 update: a report from the American Heart Association. Circulation 2017;135:e146-603.

29. Food insecurity: a public health issue. Public Health Rep 2016;131:655-7.

30. US Department of Agriculture, Economic Research Service. Definitions of food security. Available online: http://www.ers.usda.gov/topics/food-nutiriton-assistance/ food-security-in-the-us/definitions-of-food-security.aspx

31. De Marchis EH, Torres JM, Fichtenberg C, et al. Identifying food insecurity in health care settings: a systematic scoping review of the evidence. Fam Community Health 2019;42:20-9.

32. Carter MA, Dubois L, Tremblay MS. Place and food insecurity: a critical review and synthesis of the literature. Public Health Nutr 2014;17:94-112.

33. Franklin B, Jones A, Love D, et al. Exploring mediators of food insecurity and obesity: a review of recent literature. J Community Health 2012;37:253-64.

34. Seligman HK, Schillinger D. Hunger and socioeconomic disparities in chronic disease. N Engl J Med 2010;363:6-9.

35. Bruening M, Dinour LM, Chavez JBR. Food insecurity and emotional health in the USA: a systematic narrative review of longitudinal research. Public Health Nutr 2017;20:3200-8.

36. Gualtieri MC, Donley AM, Wright JD, et al. Home delivered meals to older adults: a critical review of the literature. Home Healthc Now 2018;36:159-68.

37. Kawachi I, Kennedy B, Wilkinson RG. The society and population health reader: income inequality and health (society and population health reader (paperback)). 1st ed. New York: New Press, 1999.

38. Daniels N, Kennedy B, Kawachi I. Justice is good fr our health: how greater economic equality would promote public health. Boston Review 2000;25. Available online: 
http://bostonreview.net/forum/norman-daniels-brucekennedy-ichiro-kawachi-justice-good-our-health

39. Ruger JP. Ethics of the social determinants of health. Lancet 2004;364:1092-7.

40. National Alliance to End Homelessness. The state of homelessness in America. Available online: https:// endhomelessness.org/homelessness-in-america/ homelessness-statistics/state-of-homelessness-report/

41. Coughlin SS. Invited commentary: co-occurring health conditions among women living with profound life challenges. Am J Epidemiol 2011;174:523-5; Discussion 526-7.

42. Bélanger E, Ahmed T, Vafaei A, et al. Sources of social support associated with health and quality of life: a crosssectional study among Canadian and Latin American older adults. BMJ Open 2016;6:e011503.

43. Walker RJ, Gebregziabher M, Martin-Harris B, et al. Relationship between social determinants of health and processes and outcomes in adults with type 2 diabetes: validation of a conceptual framework. BMC Endocr Disord 2014;14:82.

44. Gage-Bouchard EA. Social support, flexible resources, and health care navigation. Soc Sci Med 2017;190:111-8.

45. Stange KC, Nutting PA, Miller WL, et al. Defining and measuring the patient-centered medical home. J Gen Intern Med 2010;25:601-12.

46. Daniel H, Bornstein SS, Kane GC, et al. Addressing social determinants to improve patient care and promote health

doi: 10.21037/jhmhp.2019.09.03

Cite this article as: Coughlin SS, Mann P, Vernon M, Young L, Ayyala D, Sams R, Hatzigeorgiou C. A logic framework for evaluating social determinants of health interventions in primary care. J Hosp Manag Health Policy 2019;3:23. equity: an American college of physicians position paper. Ann Intern Med 2018;168:577-8.

47. Hammond WP, Siddiqi AA. Social determinants of medical mistrust among African-American men. In: Treadwell HM, Xanthos C, Holden KB. editors. Social determinants of health among African-American men. San Francisco: Jossey-Bass, 2013:135-60.

48. Hausmann LRM, Kwoh CK, Hannon MJ, et al. Perceived racial discrimination in health care and race differences in physician trust. Race Soc Problem 2013;5:113-20.

49. Musa D, Schulz R, Harris R, et al. Trust in the health care system and the use of preventive health services by older black and white adults. Am J Public Health 2009;99:1293-9.

50. Xanthos C. Prejudiced providers: unequal treatment as a determinant of African-American men's health. In: Treadwell HM, Xanthos C, Holden KB. editors. Social determinants of health among African-American men. San Francisco: Jossey-Bass, 2013:207-24.

51. Fiscella K, Sanders MR. Racial and ethnic disparities in the quality of health care. Annu Rev Public Health 2016;37:375-94.

52. Belgrave FZ, Abrams JA. Reducing disparities and achieving equity in African American women's health. Am Psychol 2016;71:723-33.

53. Starfield B, Gérvas J, Mangin D. Clinical care and health disparities. Annu Rev Public Health 2012;33:89-106. 